\title{
Computer-Based Simulation and Scaled Laboratory Bench System for the Teaching and Training of Engineers on the Control of Doubly Fed Induction Wind Generators
}

Jaime R. Arribas, Carlos Veganzones, Francisco Blázquez, Member, IEEE, Carlos Platero, Dionisio Ramírez, Member, IEEE, Sergio Martínez, Member, IEEE, Jose A. Sánchez, and Nieves Herrero Martínez

\begin{abstract}
Among the existing renewable sources, wind energy is reaching production rates that are becoming important on the worldwide energy scene. Since the control of these wind generators is a very technical discipline, practical teaching methodologies are of special relevance. Paradoxically, in the past, the training of engineers specializing in this area has lacked the practical component represented by field tests, due to the difficulty of access to this kind of installation. This paper presents a system designed for use both in teaching and training procedures for control strategies for wind generators with doubly fed induction generator (DFIG) technology. The system includes two phases or levels of use: the first being a simulation phase based on computer models, and the second, an advanced level which allows for the conducting of tests on a laboratory scaled workbench composed of a wind turbine emulator coupled to an electric generator. With this equipment, the effectiveness of the wind generator regulation systems can be analyzed from the point of view of the maximum power point tracking control strategy, as well as from that of the contribution produced by the wind generator to the control of the operation of the electric grid to which it is connected.
\end{abstract}

Index Terms-Control systems, educational technology, induction generators, simulation, wind power generation.

\section{INTRODUCTION}

$\mathbf{T}$ HE Kyoto Protocol resulted in a commitment by most of the countries within the European Union and its area of influence, suggesting a potential massive increase of renewable energy generation systems in its electrical power network. For example, in Spain, the total installed wind capacity at the end of
2009 was more than $18000 \mathrm{MW}(17 \%)$ of the some $98000 \mathrm{MW}$ of the total electrical generation capacity. Of particular interest is the possibility of the inclusion of wind energy as distributed generation near the demand centers, located in distribution networks [1]. Obviously, this will mean high penetration indexes in local networks. This will require collaboration from wind generators regarding stability and regulation issues [2]-[4]. In fact, some countries (Spain, Germany, Denmark, etc.) include in their legislation for the contribution of wind farms to the electrical system reliability [5]-[8].

As wind generation penetration grows, along with compliance to network regulations, higher quality response for wind generators to grid disturbances is needed, and therefore, more sophisticated control requirements are imposed on these systems.

Since it is the responsibility of the universities to teach and train future engineers on this matter, it was necessary to fulfill this technological demand [9].

Mainly due to the difficulty in accessing this kind of generator, studies on wind generation technologies are typically based on theoretical lessons, with practical experience being an absolutely necessity in this discipline. In most of the educational centers, this practical experience has been carried out only by means of computer simulation models, without the benefits brought by the actual machines, and with field tests being performed in the laboratory. The use of experimental workbenches is only available in limited cases [10]-[12].

Furthermore, regarding research tasks, an initial step in the development of new control algorithms is the utilization of computer models, with the next step being their validation in a test bench with real machines.

This paper describes a complete system dedicated to the teaching and training of engineers on the control of wind DFIG systems. This system includes two difterent ways or levels for learning:

- A "basic" level, composed of a computer simulator based on computer models of the different components of the wind generator, covering the first learning stage. This application contains a series of exercises which are programmed to guide the students' learning.

- At the second stage, the student can access an "advanced" level, where a $5-\mathrm{kW}$ power laboratory workbench simulates, in a reduced scale, the actual turbine-generator set. 


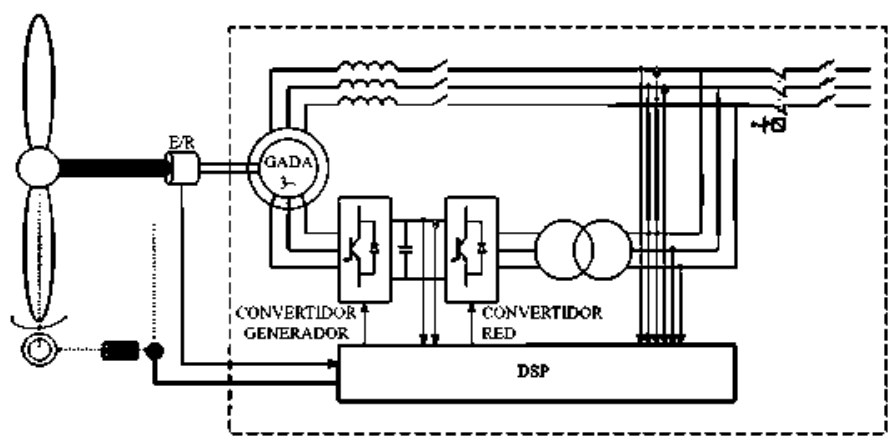

Fig. 1. General layout of the DFIG wind generator.

Using this equipment and always assisted by a supervisor, the students can test the control strategies which have been developed in the previous stage, so as to reinforce the acquired knowledge, upon analyzing the results.

The doubly fed induction generator (DFIG) technology was chosen because it is one of the most extensive wind generation technologies and because it is highly suitable for the implementation of advanced generation features [13]-[15].

The use of this computer and laboratory equipments was designed for both research and teaching purposes.

\section{DESCRIPTION OF DFIG TECHNOLOGY FOR WIND GENERATION}

Fig. 1 presents a block scheme containing the constitutive elements of the generator group of a wind generator with DFIG technology.

It is a controlled AC drive based on a wound rotor induction machine (DFIG), whose stator is directly connected to the grid (through a coupling reactance) while the connection between the rotor and the grid is made through an electronic power regulated system, composed of two electronic converters working back to back, serving as a bi-directional rotor cascade for the slip control.

An adequate program controlling these two converters, which runs on a DSP, allows for the regulation of the system working point in the following manner:

- The "generator side converter" is connected to the rotor phases and it constantly controls the torque and speed of the drive operating point, thus regulating the power extracted from the wind turbine. Furthermore, this same converter takes part in the regulation of the reactive power delivered to the grid through the generator's stator.

- The "grid side converter" is connected to the later converter and the grid, and its tasks include the following: First, it maintains the voltage level in the DC bus between the two converters, so that a portion of active power is interchanged between the rotor and the grid, according to the slip imposed by the speed regulation of the previous converter. Second, this converter participates in the regulation of the reactive power delivered to the grid by the entire system.

The following section describes in detail the composition, working procedure, and methodology employed in the utilization of the equipment that has been developed for the teaching and training of this technology in the two phases mentioned:
— simulation with computer models;

- experimental tests in laboratory workbench.

\section{DESCRIPTION AND USE OF THE TEACHING/TRAINING COMPUTER SIMULATOR}

\section{A. Description of the Simulation Models}

In order to cover the first learning level, a full computer simulator for the referred technology has been developed. It has been programmed using the Matlab-Simulink environment.

The algorithms that have been employed in the different models of this system are especially robust and simple, because part of their programming code must be accessible to the user. The simulator, whose scheme is presented in Fig. 2, is composed of the following main blocks (from lett to right in the figure).

Block containing the dynamic model of the rotational regulated drive (turbine, transmission, etc.), block with the control system, block containing the DFIG model, and finally, a block where all of the measurements of the electric variables at the wind generator's terminals are performed.

The model of the mechanical system which includes the wind turbine "Turbine", its regulation system "MPPT", and the transmission system "Shaft Torque" does not present any novelty; therefore, its description is referred to in [16].

The block "Control", represented in Fig. 3, determines the reference value of the rotor voltage " $U_{r}$ ", which will be consistently established by the generator side converter. This calculation is performed using the references of the active and reactive power $P$ and $Q$, which are constantly received from the block "MPPT", establishing the system control strategy. In this last operation, the grid voltages in two stator phases are needed "U_R, U U, ".

The block "Machine" from Fig. 2 is represented in detail in Fig. 4, and includes a space-phasor model of the wound rotor asynchronous generator which works in the following way: starting from the rotor phase voltages " $\mathrm{U}_{\mathrm{r}_{-} \mathrm{A}}, \mathrm{U}_{\mathrm{r}_{-} \mathrm{B}}$, and $\mathrm{U}_{\mathrm{r}_{-}} \mathrm{C}$ " received from the "Control" block, it determines the value of the EMF induced in the stator (UsD) which is needed to produce the adequate current in order to inject into the grid the active and reactive powers $P$ and $Q$, equal to their reference values. In order to perform this calculation, the speed value "W $W_{d, D}$ ", provided from the block "Shaft Torque" (n), is needed [17].

Since the main objective of this system is to offer better comprehension of the possible control strategies concerning this type of wind generator, special care will be taken in describing the control block. Here is where the student will be able to make modifications and adjustments, and check the obtained results, thus learning in a positive and efficient manner.

The basic control strategy which is initially proposed to the student in this system, for the two existing converters, is presented in the two following parts.

\section{B. Regulation Strategy for the "Generator Side Converter"}

The control of the "generator side converter" is the key of this type of wind generator. Here the programming of a simple and robust control strategy is presented. 


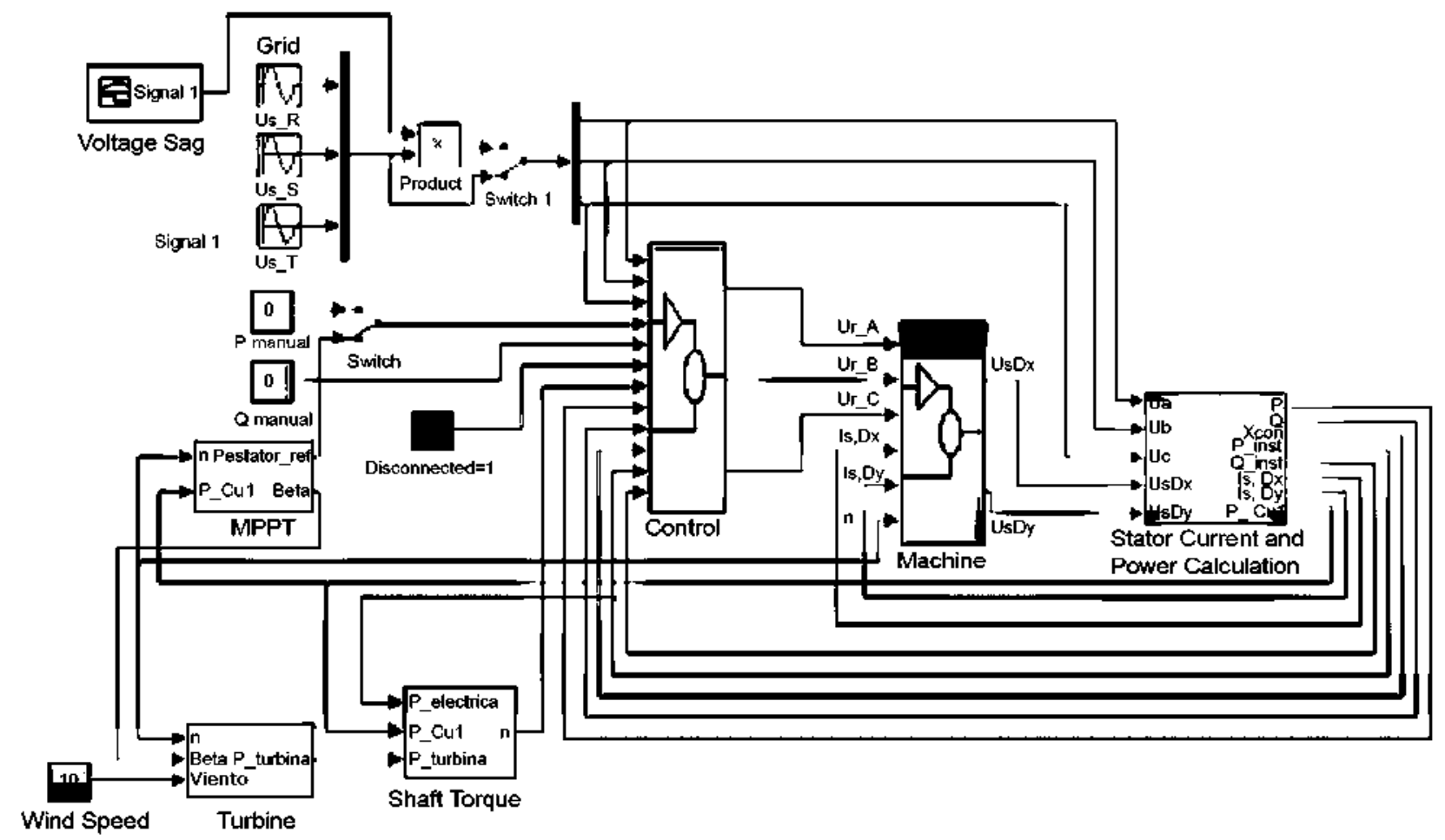

Fig. 2. Block layout of the DFIG simulation system.

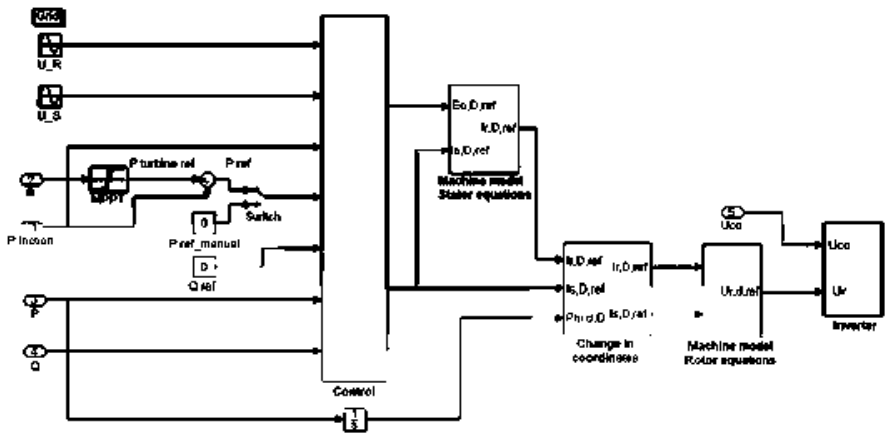

Fig. 3. Block layout of the control system.

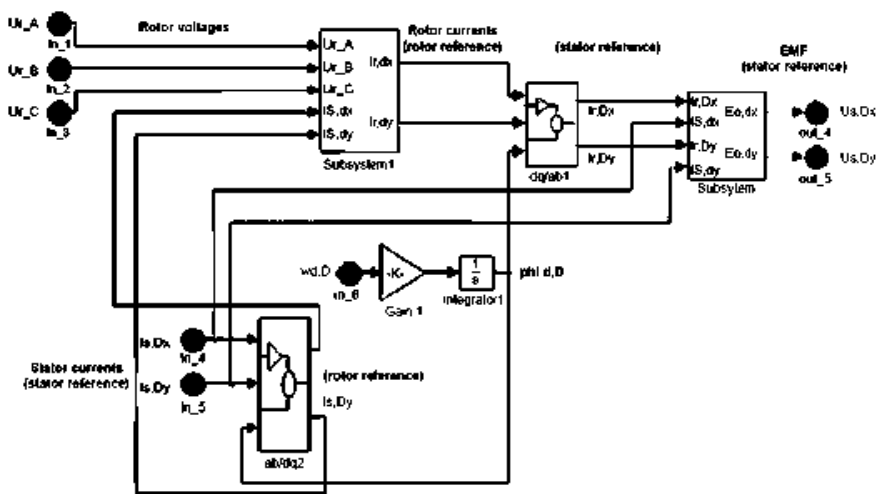

Fig. 4. Scheme of the DFIG motel.

1) Stator EMF Calculation: In Fig. 5, the control scheme for the generator side converter is presented.

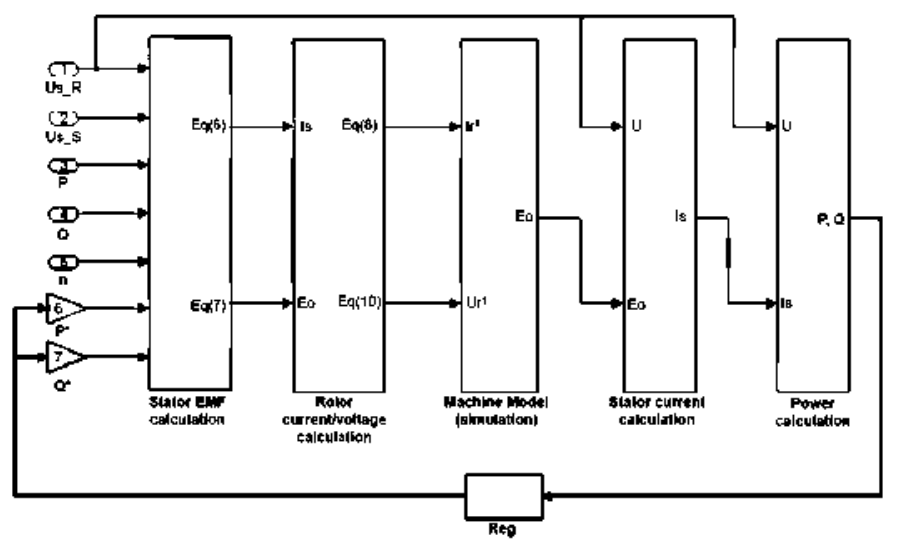

Fig. 5. Control scheme of the generator-side converter.

The system reads the stator voltage, the machine speed, and the reference values for the active and reactive power $\left(\mathrm{P}^{*}\right.$ and $\left.\mathrm{Q}^{*}\right)$. With this information, it calculates the voltage necessary in the stator terminals $\varepsilon_{0}$, so that once connected to the grid through a coupling reactance, there will be a power transfer, in accordance with the reference values.

The procedure followed to calculate the stator voltage vector $\varepsilon_{0}$ is the following.

Using the model of Fig. 6, which establishes the relationship between the space phasors representing the stator voltage $\varepsilon_{0}$ and current I with the grid voltage $\mathrm{V}$ ( $X_{s}$ is the coupling reactance)

$$
\overrightarrow{\varepsilon_{o}}=\vec{V}+j \cdot X_{S} \cdot \vec{I}
$$




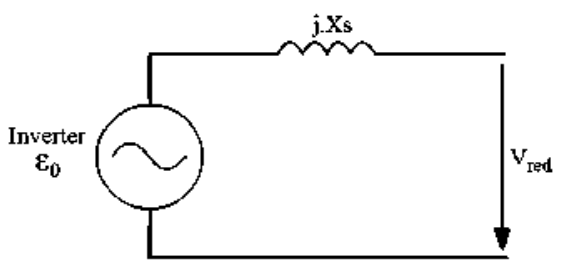

Fig. 6. Grid connection of the DFIG.

the $\varepsilon_{0}$ orthogonal components are obtained, expressed in the reference established by the grid voltage phasor $\left(\bar{V}=V_{\alpha}+\right.$ $j \cdot V_{\beta}=0$; with $V_{\beta}=0$ )

$$
\varepsilon_{o \alpha}+j \cdot \varepsilon_{o \beta}=V_{\alpha x}-X_{S} \cdot I_{\beta}+j \cdot X_{S} \cdot I_{\alpha} .
$$

In order to calculate the modulus and angle of the stator voltage phasor

$$
\begin{aligned}
\left|\overrightarrow{\varepsilon_{o}}\right| & =\sqrt{\left(V_{\alpha}-X_{S} \cdot I_{\beta}\right)^{2}+\left(X_{S} \cdot I_{\alpha}\right)^{2}} \\
\delta & =\operatorname{arcsen}\left(\frac{\varepsilon_{0 \beta}}{\left|\overrightarrow{\varepsilon_{0}}\right|}\right)=\operatorname{arcsen}\left(\frac{X_{S} \cdot I_{\alpha}}{\left|\overrightarrow{\varepsilon_{0}}\right|}\right)
\end{aligned}
$$

the stator current must be determined. To determine the current, the system will start from the power commands, which are known.

From the active and reactive power space phasor expressions

$$
\left\{\begin{array}{l}
P=\frac{2}{3} \cdot\left(V_{\alpha} \cdot I_{\alpha \mathrm{r}}+V_{\beta} \cdot I_{\beta}\right) \\
Q=\frac{2}{\sqrt{3}} \cdot\left(V_{\beta} \cdot I_{\alpha}-V_{\alpha} \cdot I_{\beta}\right)
\end{array}\right.
$$

the value of the components of the stator current phasor is obtained:

$$
\left\{\begin{array}{l}
I_{\alpha}=\frac{3}{2} \cdot \frac{P}{V_{\alpha}}=\frac{3}{2} \cdot \frac{P}{|\vec{V}|} \\
I_{\beta}=-\frac{\sqrt{3}}{2} \cdot \frac{Q}{V_{\alpha}}=-\frac{\sqrt{3}}{2} \cdot \frac{Q}{|\vec{V}|} .
\end{array}\right.
$$

Finally, the stator voltage phasor which determines in that instant the desired $P$ and $Q$ interchanged with the grid is obtained:

$$
\left\{\begin{array}{l}
\left|\overrightarrow{\varepsilon_{o}}\right|=\sqrt{\left(|\vec{V}|+\frac{\sqrt{3}}{2} \cdot \frac{X_{S} \cdot Q}{\mid \vec{V}}\right)^{2}+\left(\frac{3}{2} \cdot \frac{X_{S} \cdot P}{|\vec{V}|}\right)^{2}} \\
\delta=\operatorname{arcsen}\left(\frac{\frac{3}{2} \cdot x_{s} \cdot P}{\left|\overrightarrow{\varepsilon_{0}}\right| \cdot \mid \vec{V}}\right)
\end{array}\right.
$$

In Fig. 7, the phasor diagram of the stator voltage and current of the generator are presented, including their relation to the active and reactive power interchanged with the grid.

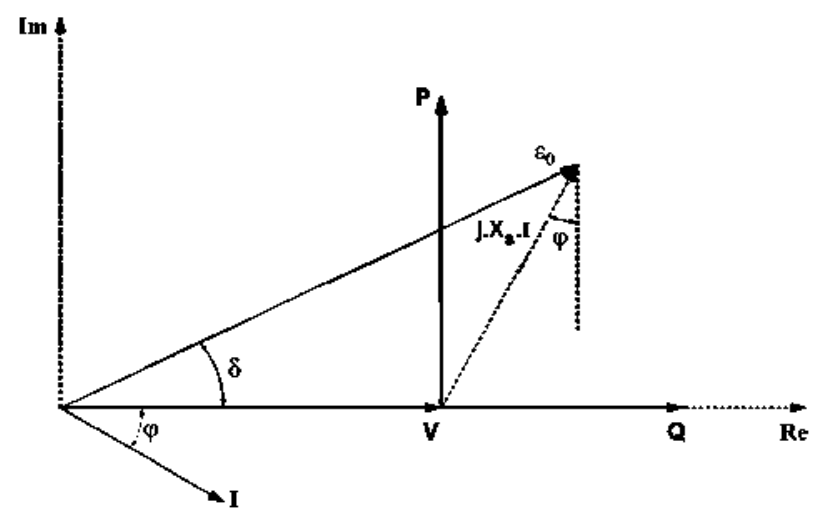

Fig. 7. Phasot diagram of the grid connection.

2) Rotor Phase Current Calculation: Once the required stator voltage phasor for the generator has been calculated, the stator voltage equation from the machine model (8) (where $\mathrm{U}_{\mathrm{S}}=\varepsilon_{0}$ ), is used in order to calculate the current that should be injected into the rotor so that, according to the machine speed and the stator currents existing at that moment, the desired electromotive force (e.m.f.) will be induced in the stator (see Fig. 5). These currents, expressed in the reference rotating with the rotor, are those that the converter must inject, through the slip rings in each rotor phase. If this converter is voltage controlled and not current controlled, then the machine model must be reused [rotor voltage $(10)$ ] in order to convert the calculated rotor currents into their corresponding rotor voltages:

$$
\vec{U}_{S, D}=R_{S} \cdot \vec{i}_{S, D}+L_{S} \cdot \frac{d \vec{i}_{S, D}}{d t}+L \cdot \frac{d \vec{i}_{r, D}^{\prime}}{d t}
$$

where

$U_{s, D} \quad$ stator voltage space phasor, with respect to the stator reference ( $D$ axis);

$i_{s, D} \quad$ stator current space phasor, with respect to the stator reference (D axis);

$i_{r, D}^{\prime} \quad$ rotor current space phasor referred to the stator, with respect to the stator reference ( $\mathrm{D}$ axis);

$R_{S} \quad$ stator resistance;

$L \quad$ magnetizing inductance;

$L_{S} \quad$ stator inductance

$$
L_{S}=L_{S \sigma}+L
$$

and $L_{S \sigma}$ is the stator leakage inductance

$$
\vec{u}_{r, d}^{\prime}=R_{r}^{\prime} \cdot \vec{i}_{r, d}^{\prime}+L_{r} \cdot \frac{d \vec{i}_{r, d}^{\prime}}{d t}+L \cdot \frac{d \vec{i}_{S, d}}{d t}
$$

where

$u_{r, d}^{\prime} \quad$ rotor voltage space phasor referred to the stator, with respect to the rotor reference ( $d$ axis);

is,d stator current space phasor, with respect to the rotor reference (d axis); 


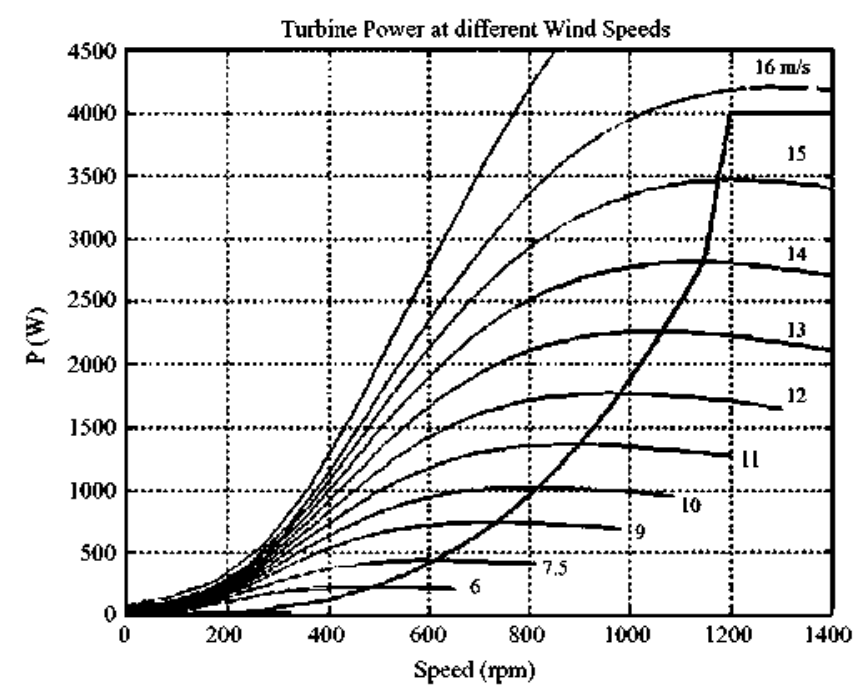

Fig. 8. Turbine power at different wind speeds.

$$
\begin{array}{ll}
q_{r, d}^{\prime} & \text { rotor current space phasor referred to the stator, } \\
& \text { with respect to the rotor reference (d axis); } \\
R_{r}^{\prime} & \text { rotor resistance, referred to the stator; } \\
L_{r} & \text { rotor inductance }
\end{array}
$$

$$
L_{r}=L_{r \sigma}^{\prime}+L
$$

and $L_{r \sigma}^{\prime}$ is the leakage rotor inductance, referred to the stator.

3) $P Q$ Controller Operation: Upon calculating how to feed the rotor in order to deliver, through the stator, the active and reactive power according to the references, the machine model, (8) and (10), is reused in order to simulate the effect on the generator (see Fig. 4).

Once the voltage induced in the stator is known, it is compared with the grid voltage at the other side of the coupling reactance and the stator current is calculated. Starting from the value of the stator voltages and currents, the actual active $P$ and reactive Q powers interchanged with the grid are calculated. These powers are compared with their respective references, $\mathrm{P}^{*}$ and $Q^{*}$, so that a regulator can correct the error in the next calculation to be performed on the voltages needed to be induced in the stator.

Once the machine is connected to the grid, the system may be operated in two different modes in order to set the commands for the active and reactive powers. One possibility is setting the $P$ and $Q$ references in the manual mode, and the other possibility is the activation of the maximum power point tracking (MPPT) operating mode. In the latter case, the most typical is to operate the generator with zero reactive power reference $\left(Q^{*}=0\right)$. In Fig. 8, the curve used to obtain the power reference for any operating speed of the wind generator working in maximum power point tracking mode is shown.

\section{Regulation Strategy for the "Grid Side Comerter"}

In Fig. 9, a block diagram showing the input and output variables of the grid side converter control system is schematically presented. The system works as follows: the control variables

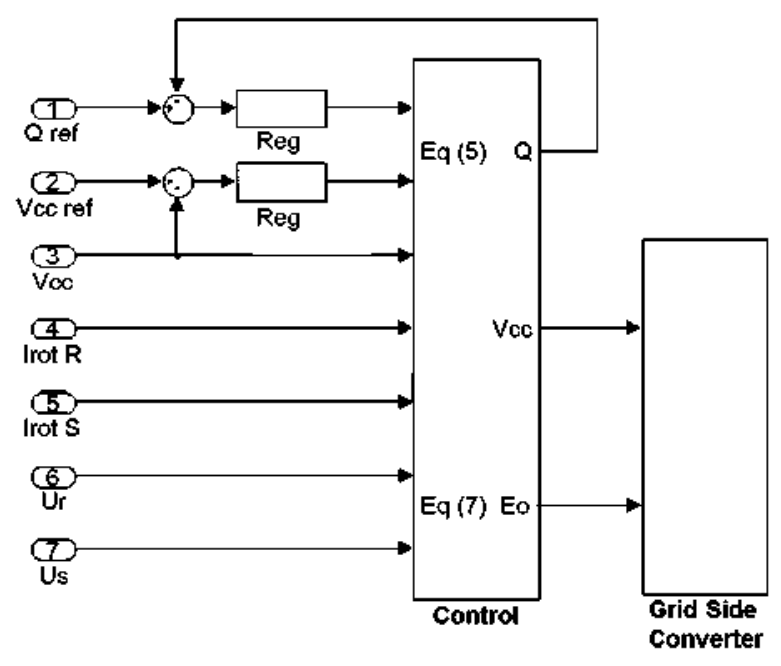

Fig. 9. Control scheme of the grid side converter.

are the $\mathrm{DC}$ bus voltage $(\mathrm{Vcc})$ and the reactive power exchanged with the grid through the rotor line (Q). The inputs are the reference values of the variables previously mentioned as well as the $\mathrm{AC}$ voltages and currents in the rotor line. The system uses the grid voltages that are measured in the stator, now considering the transformer relation (see Fig. 1), and reads the currents in the rotor line so as to calculate the active and reactive powers exchanged with the grid through the rotor line. After this calculation, the system regulates the three phase voltages that the converter should generate in order to accomplish the DC bus voltage and reactive power references. This calculation is performed in the same manner as for the previously described generator control scheme [(1) to (7); see Fig. 7].

\section{Working Methodology for Simulator Teaching and Training}

In order to familiarize the computer simulator user with both the proposed wind generator model and the control system, some specific tasks that will guide the student's learning process are offered.

- First, the simulation model is delivered to the student, including a mistake that has been thoroughly inserted so that he/she must find and solve it. This way, the student is "guided" to review in depth, the model that he/she is going to use.

- Next, the student receives the functioning model, and he/she is asked to search for determined variables whose evolution must be plotted during different working conditions. With this task, it is assumed that the student perfectly understands how this type of generator and wind technology works.

- Finally, the student is asked to modify the proposed regulation strategy. With this task, it is assumed that the student will be able to compare different control strategies, from an energy-efiiciency point of view, quick response, etc.

1) Case Study. Simulation Results: To demonstrate how this simulation system works, we present the case in which an increase in wind forces the generator to raise its speed to a value over the synchronous speed ( 1000 r.p.m.), while the references of active $(2.500 \mathrm{~W})$ and reactive power $(-1.000 \mathrm{VAr})$ that the 

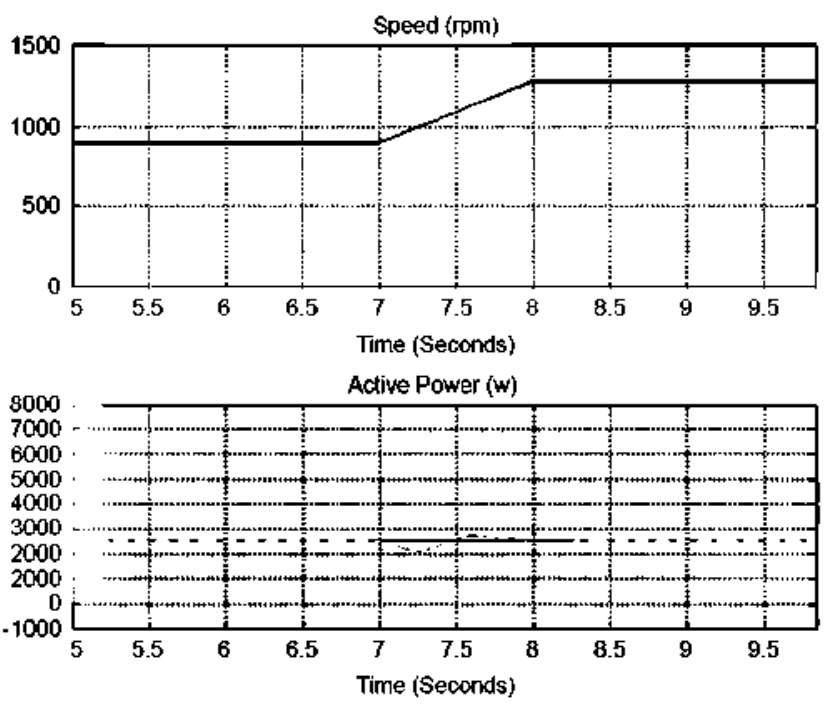

Reactive Power (VAr)
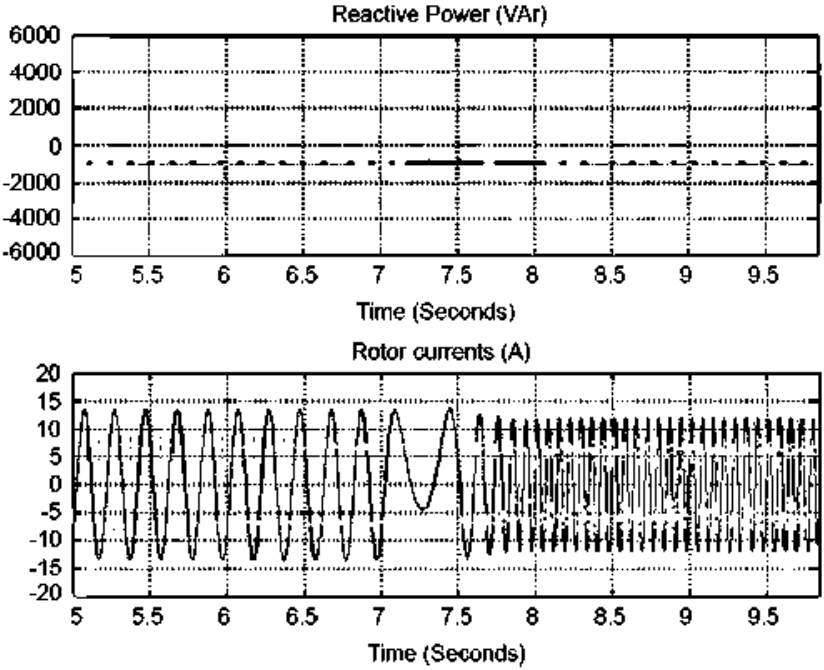

Fig. 10. Simulation results.

stator deliver to the grid remain at the same value. Although this manual mode of operation is not commonly employed in wind generators, it has been specifically designed for this training system because it provides increased possibilities of offering an improved study and an increased understanding of this type of machine.

In Fig. 10, it can be observed the change in the sequence of the currents injected into the rotor that is produced after the speed raises over the synchronous value, while the active and reactive power interchanged with the grid through the stator are kept constant.

\section{DESCRIPTION OF THE TEACHING/TRAINING EXPERIMENTAL WORK-BENCH}

\section{A. Workbench Description}

As it can be seen in the picture shown in Fig. 12, the bench is composed of two controlled electrical drives, the wind turbine emulator and the electric generator, coupled on the same shaft.

1) Wind Turbine Emulator: The wind turbine emulator (WTE) consists of a DC motor [(1) in Fig. 12] driven by a

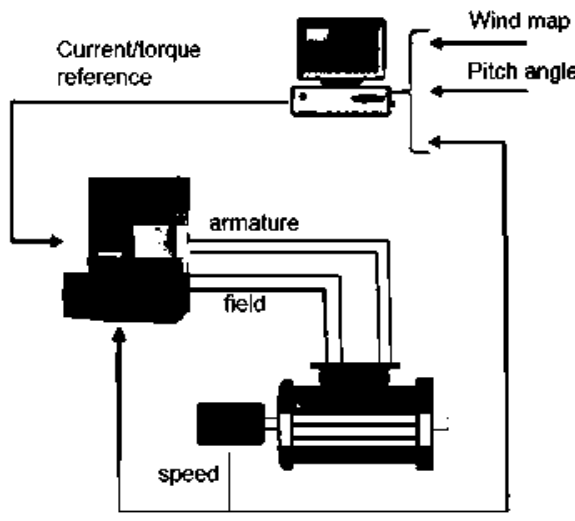

Fig. 11. WTE control scheme.

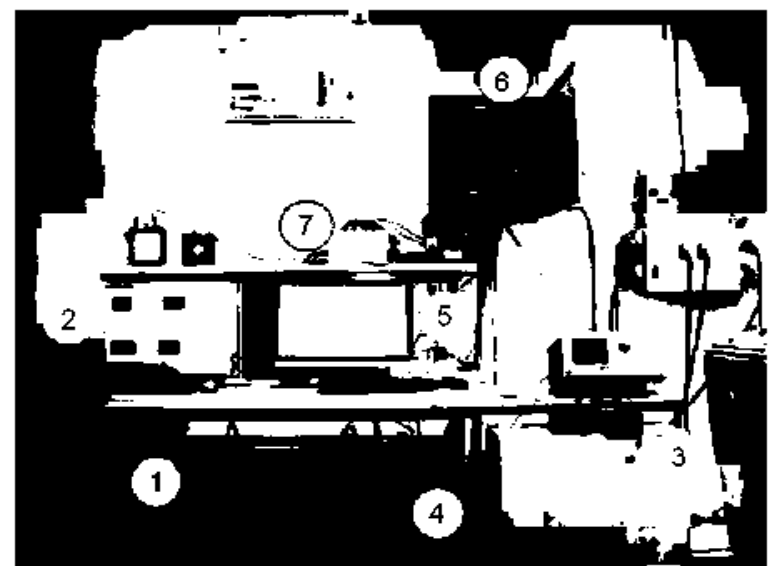

Fig. 12. Laboratory WTE-DFIG scaled bench

commercial microprocessor-based DC converter that is easily configurable [(3) in Fig. 12]. A detailed description of this part of the workbench is presented in [18]. The converter is controlled by means of a PC [(2) in Fig. 12] and an input-output data acquisition device that has been programmed using the commercial software LABVIEW. Fig. 11 shows a scheme of the developed WTE.

The specific components used in the presented emulator of the variable-pitch wind turbine are the following:

- A 7.5-kW, 400-V, 1000-rpm DC machine. It is mechanically coupled to the generator to transmit the desired torque.

- An AC/DC Siemens-Simoreg converter for DC drives. It supplies the suitable voltage/current to the DC machine in order to achieve the specified torque reference.

- An NI PCI-6014 Data Acquisition System. It calculates the torque reference from a pitch reference and the measured rotational speed.

This set reproduces the dynamic behavior of the wind turbine, including the blade pitch angle regulation, from a previously programmed time evolution of the wind speed.

2) Doubly Fed Asynchronous Generator: The doubly fed induction generation (DFIG) system, presented in Fig. 12, is composed of: 


\section{St Sistema de control Generador Asincrono Doblemente Alimentado}
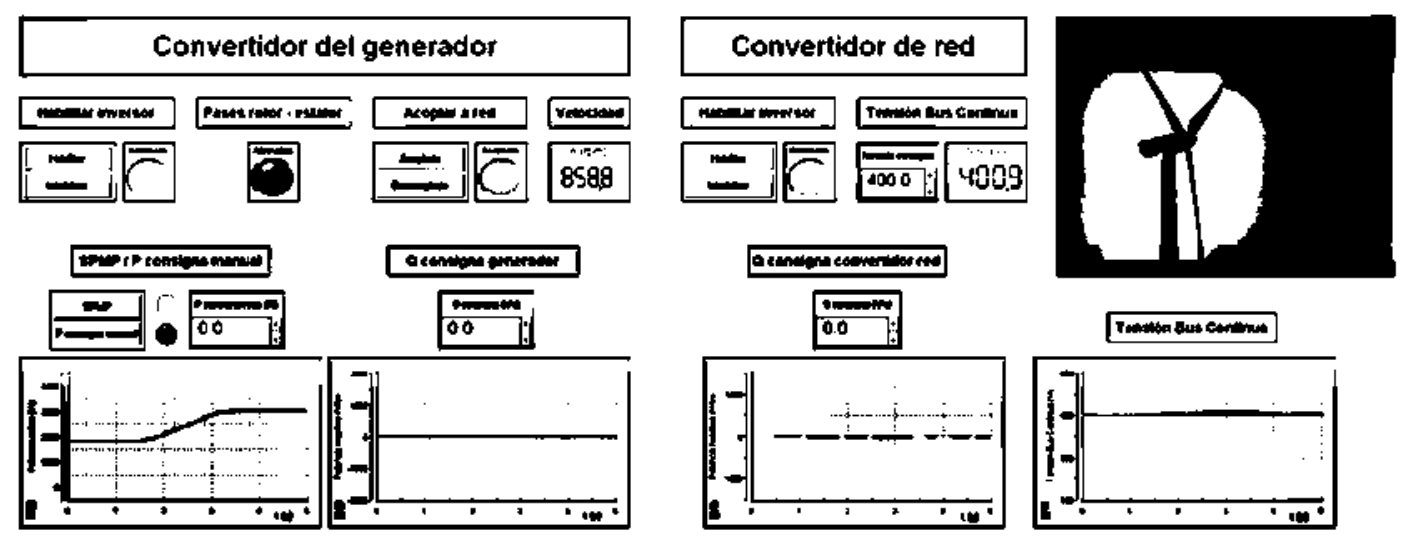

Fig. 13. Screen capture of the laboratory control application for the DFIG

- a 5.5-kW, 6-pole, 400-V wound rotor asynchronous machine ["GADA" in Fig. 1 and (4) in Fig. 12];

- an AC/DC, 1200-V, 35-A three-phase controlled IGBT converter ["Conv. Red" in Fig. 1 and (6) in Fig. 12] (SKS 35F B6U+E1CIF+B6 CI $21 \mathrm{~V} 12$ ).

When working below the synchronous speed, it rectifies the voltage/currents from the grid to feed the DC bus from which the generator converter will feed the wind generator rotor. Above that speed, it will control the DC bus voltage delivering power to the grid. At all times, the control system of this converter regulates the reactive power exchanged with the grid to which the generator's rotor is connected.

- A DC/AC 1200-V, 30-A, three-phase controlled IGBT"s converter ["Conv, Gen," in Fig. 1 and (6) in Fig. 12] of the same type as the previous. It feeds the DFIG's rotor with $\mathrm{AC}$ obtaining the energy from the $\mathrm{DC}$ bus. The control system calculates how the rotor phases must be fed so that the generator's stator delivers the maximum electric power associated to any wind conditions to the grid. The control system also regulates the reactive power exchanged with the net through the generator's stator by means of this converter.

- A DSP-based control system composed of a dSPACE 1104 Development Board [DSP in Fig. 1 and (5) in Fig. 12]. This hardware allows for the simultaneous controlling of the IGBT firing signals in the DC/AC generator side converter and those of the AC/DC grid side converter. The interface included with this system allows for the real-time tracking of the change of any variable in the entire generation system.

- A Hall Effect sensors box for adapting voltage and current measurements to the DSP input channels [(7) in Fig. 12].

Fig. 13 shows the screen representation of the laboratory application showing some of the main variables of the process during a ramp time evolution of the wind.

Note that the reactive power remains at zero following its reference value, while the active power delivered to the grid increases with the speed according to the reference imposed by the "Maximum Power Point Tracking". Fig. 13 also shows the reactive power interchanged with the grid through the rotor, as well as the voltage existing in the DC bus. The horizontal axis represents time in seconds.

\section{B. System Operation}

The described system is designed to be operated in the following manner.

1) The wind turbine emulator is initiated using a specific wind reference. The WTE control system reads the turbine speed and the pitch angle reference from the generator control system (DSP).

2) When the generator control system detects the minimum speed at which the wind generator (DFIG) must be started, both the grid converter and the generator converter are started in order to prepare the system for connection to the grid.

3) Once the DFIG stator generates three voltages equal to those of the grid to which it will be connected, the grid connection switch is closed.

4) When the generator stator is connected to the grid, the generator control system can operate in two different modes: The manual mode in which the user can specify the active and reactive power references, and the automatic mode in which the system begins searching for the maximum power operating point according to the existing wind conditions imposed by the WTE. This last option corresponds to the normal operation of a real wind DFIG.

5) At the same time, the grid converter control system maintains the DC bus voltage equivalent to the reference value.

6) From this point on, the system works automatically and the only parameter that can be modified is the WTE current/ torque reference.

7) At any turbine speed, the DFIG will deliver the maximum active power established by a reference table, including the higher speed values at which the pitch angle must be changed. The generator control system normally operates maintaining zero reactive power interchanged with the grid. Nevertheless, the system may be operated with any other reactive power reference that is required from the network operator. 
8) According to the grid converter control system, it is important to remember that when the wind turbine operates below the synchronous speed, this converter acts as a rectifier, allowing the energy to flow from the grid to the rotor. But when the turbine speed increases above the synchronous value, it works as an inverter, delivering power from the rotor to the grid. Regardless, this converter also collaborates in the global reactive power control.

\section{Training Methodology. Tests to be Performed}

In order to familiarize the user with the installation, a complete user guide for the system operation is provided. This guide contains the description and technical characteristics of all the system components. Following this operation guide and always under the instructor's supervision, the user may perform the following tests.

1) Check for the relative position of the space phasors representing the stator and rotor magnetic fields in the following cases.

- In different wind generator operating conditions with different $\mathrm{P}$ and $\mathrm{Q}$ commands and working at different speeds. This test must be performed with the system working in the manual mode.

- During a transient such as the wind generator's connection to the grid and the maximum power point tracking or a variation of the speed caused by a change in the wind conditions, etc.

The main goal of these tests is to empirically validate previous studies carried out in the simulation phase.

2) Analyze the active and reactive powers and register the voltage, current, and frequency existing in the stator and rotor at different operating conditions corresponding to different rotating speeds: sub-synchronous, synchronous, and super-synchronous.

Again, the main goal of these tests is to determine, in an actual installation, how this wind technology works, and to empirically validate studies that are similar to those previously performed in the simulation phase.

3) Test new control strategies for partial or entire systems or perform variations on the proposed control algorithm.

In this case, the user can act on one or both converters control systems. Since the program code of both the control of the grid side converter and the control of the generator side converter is accessible to the user, variations may be performed and/or changes made to the initially-proposed regulation strategy.

It is important to note the versatility of this system, which constitutes an excellent tool for the research of control algorithms concerning this type of wind generator.

It is also worth mentioning, as an example, that the proposed regulation strategy for this system can be either substituted by another one, such as DTC or DPC, or modified so as to allow the system to ride-through a grid incidence such as voltage sag or a slight frequency variation.

\section{Case Study. Laboratory Results}

To demonstrate the operating possibilities of this system, we present the results of a specific test consisting of the pro-
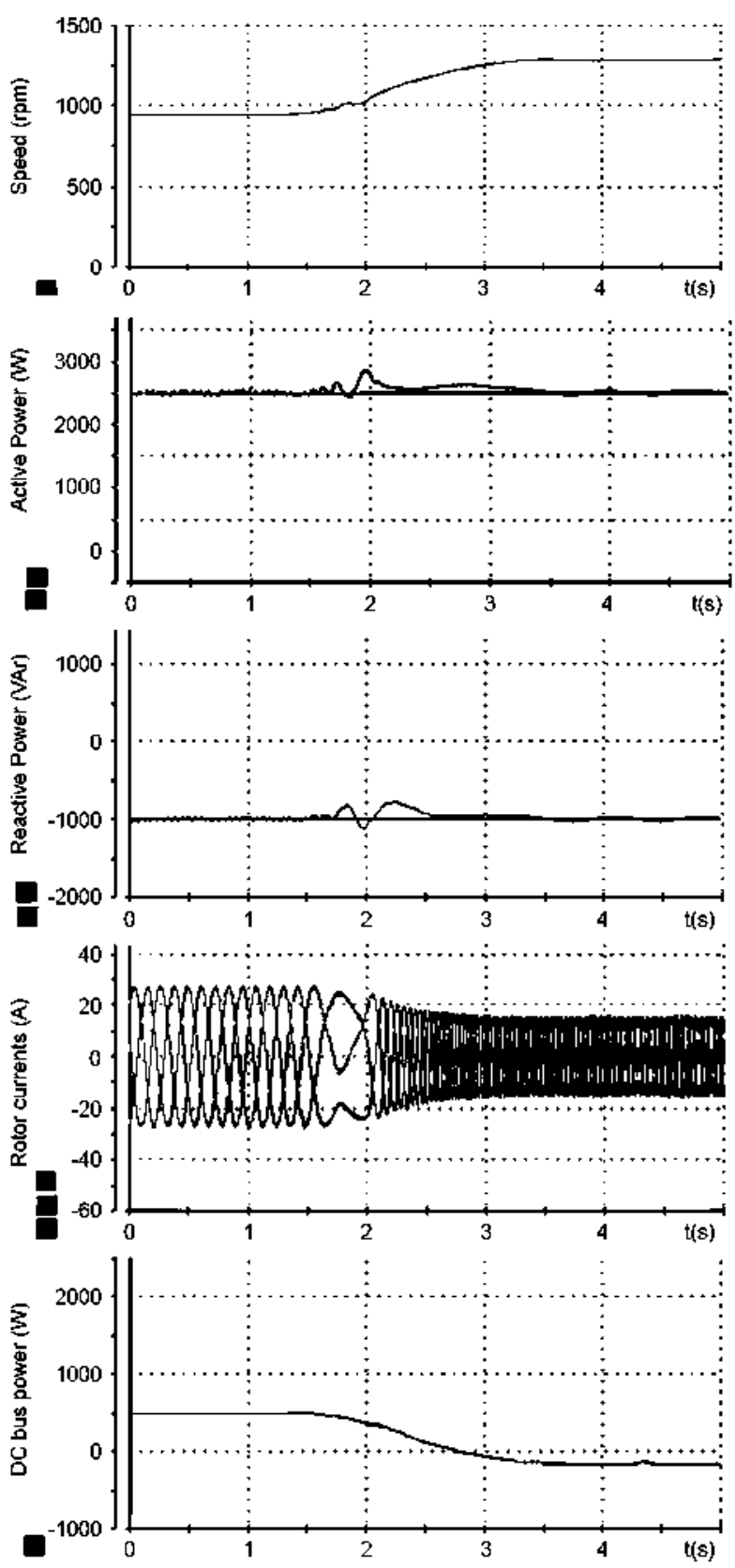

Fig. 14. Laboratory results.

duction of an increment of the wind speed while operating the system on manual reference mode. This test, whose results are presented in Fig. 14, is the same test that was presented in the simulation phase (see Fig. 10). The quid of this test is that the wind increase carries an increment of the machine rotating speed which increases from 900 r.p.m., under synchronous speed (1000 r.p.m.), to a super-synchronous speed 1280 r.p.m. Fig. 14 shows the evolution of the amplitude, the frequency, and the phase angle of the three currents injected into the rotor, as well as the value of the active $P$ and reactive $Q$ power interchanged with the grid through the stator, whose values follow at all times, the constant references established for this test $\left(\mathrm{P}_{\text {ref }}=2.500 \mathrm{~W}\right.$ and $\left.\mathrm{Q}_{\text {ref }}=-1000 \mathrm{VAr}\right)$. In Fig. 14, it is also presented, together with the speed evolution, the power consumed through the DC bus, which feeds the rotor. 
It is important to remark that, according to the behavior of this type of machine, the power consumed through the rotor becomes negative above the synchronous speed [from $t=2 \mathrm{~s}$ in Fig. 14(a)] and after supplying the rotor losses [from $t=2,8 \mathrm{~s}$ in Fig. 14(e)].

\section{CONCLUSIONS}

Since wind generator control is a very specialized field with deep technological content, practical learning regarding this matter is especially relevant.

Unfortunately, it is very common that the academic instruction of engineers in this field lacks the practical component of in-field tests, due to difficult access to these installations. In this paper, a complete learning and training system for the control strategies of wind generators with doubly fed asynchronous machines has been presented in depth, so as to allow for its reproduction.

This system includes both a training phase based on computer simulation as well as another phase based on real tests performed on a scaled laboratory workbench composed of a wind turbine emulator coupled to an electrical generator. On the one hand, the system allows the student to thoroughly study the control system of the two converters which connect the generator rotor to the grid. This is achieved by means of the simulation of different maneuvers and different operating conditions. The simulation is performed by programming the control strategy to be tested, together with a space vector model of the asynchronous generator. On the other hand, the same control strategy that has been tested in simulation can be directly programmed on the DSP of the laboratory rig. In this case, the algorithm running on the DSP controls the real converters that feed the rotor of a real generator, which is driven by a machine emulating the wind turbine.

This system is ideal both for the teaching/training of engineers within the wind generation field as well as for use as a research platform for this kind of wind technology. A possible application for this system would be the implementation of different control schemes and the study of their behavior when different grid perturbations occur (voltage sags, frequency variation, etc.).

\section{REFERENCES}

[1] Y. M. Atwa, E. F. El-Saadany, M. M. A. Salama, and R. Seethapathy, "Optimal renewable resources mix for distribution system energy loss minimization." IEEE Trans. Power Syst., vol. 25, no. 1, pp. 360-370. Feb. 2010.

[2] J. A. Sánchez, C. Veganzones. S. Martínez. F. Blázquez, N. Herrero, and J. R. Wilhelmi, "Dynamic model of wind energy conversion systems with variable speed synchronous generator and full-size power converter for large-scale power system stability studies." Renewab. Energy. vol. 33, no. 6. pp. $1186-1198$, Jun. 2008.

[3] C. Veganzones, S. Martínez, and F. Bláziuez, "Large scale integtation of wind energy into power systems." Elect. Power Qual. Util. Mag. vol. 1. no. 1, pp. 15-22, Apr. 2005.

[4] W. L. Kling and J. G. Slootweg, "Wind turbines as power plants," in Proc. IEEE/Cigré. Workshop Wind Power and the Impacts on power Systems, Oslo. Norway. Jun. 2002.
[5] C. V. Nicolas. F. Blazquez, D. Ranirez. M. Lafoz, and J. Iglesias, "Guidelines for the design and control of electrical generator systems for new grid connected wind turbine generators," Proc. IECON.2002, vol. 4. pp. 3317-3325.

[6] D. J. Burke and M. J. O' Malley. "Maximizing firm wind connection to security constrained transmission networks," IEEE Trats. Power Syst., vol. 25. no. 2, pp. 749-759. May 2010.

[7] Elkraft System, Eltra. Wind Turbines Connected to Grids With Volt. ages Above $100 \mathrm{kV}$. Technical Regulation for the Properties and the Regulation of Wind Turbines, Nov. 2004.

[8] L. Butler and K. Neuhoff. "Comparison of feed-in tariff, quota and auction mechatisms to support wind power development," Rettewab. Energy, vol. 33, no. 8, pp. 1854-1867, Aug. 2008.

[9] P. Jennings. "New directions in renewable energy education," Re. newab. Energy, vol. 34, no. 2, pp. 435-439, Feb. 2009.

[10] B. Brännbacka and T. Vekata, "A system for education of wind power at the University of Vaasa." in Proc. Nordic Workshop Power and Industrial Electrontics, Trondheim, Norway, 2004.

[11] D. Ramirez, C. Veganzones, and F. Blazguez, "Adaptation of floating point DSP-based technology for small variable-speed wind turbine," IEE E Trans. Energy Convers. vol. 22. no. 2. pp. 376-382. Jun. 2007.

[12] D. Ramitez, S. Martinez, J. Rodriguez, C. Carteto, and M. Blanco, "Educational tool for the inplementation of electric drives control system with real time data exchange," Int. J. Eng. Educ. vol. 25. no. 1, pp. 24-32, 2009

[13] P. Lok-Fu and V. Dinavahi, "Real-time simulation of a wind energy system based on the doubly-fed induction generator," IEEE Trans. Power Syst., vol. 24, no. 3, pp. 1301-1309, Aug. 2009.

[14] J. F. M. Padron and A. E. F. Lorenzo. "Calculating steady-state operating conditions for doubly-fed induction generator wind turbines," IEEE Trans. Power Syst., vol. 25, no. 2, pp. 922-928, May 2010.

[15] M. Chinchilla S. Arnalte, J. C. Burgos, and J. L. Rodríguez, "Power linits of grid-connected modern wind energy systems," Renewab. En. ergy, vol. 31, no. 9, pp. 1455-1470, Jul. 2006.

[16] C. Veganzones, S. Martínez, J. R. Wilhelmi, J. A. Sánchez, and N. Herrero, "Response of a variable speed synchronous wind generator to voltage dips." in Proc. Itt. Conf. Electrical Machines (ICEM), Cracow, Poland, Sep. 2004, pp. 614-618.

[17] V. Akhmatov, "Variable-speed wind turbines with doubly-fed induc. tion generators, Part I: Modelling in dynamic simulation tools." Wind Eng., vol. 26, no. 2. pp. 85-108, 2002.

[18] C. Veganzones, D. Ramirez, F. Blazquez, M. Blanco. S. Martinez. J Rodriguez, C. Platero, J. A. Sanchez, and N. Hertero, "New platform for experimental education in electrical generation based on wind energy systems." Int. J. Eng. Educ, vol. 25, no. 4. pp. 84 1-848, 2009.

Jaime R. Arribas was born in Madrid, Spain, in 1968. He received the Dipl. degree in electrical engineering and the Ph.D. degree in industrial engineering from the Universidad Politecnica de Madrid (UPM), Madrid, Spain. in 1993 and 2000 , respectively.

Since 1992. he has been with the Electrical Engineering Department at the Faculty of Industrial Engineers at UPM. teaching graduate and postgraduate courses in electrical machines and their control. He has coordinated the Educational Innovation Group of Electric Machines (GIEME) since 2005.

Carlos Veganzones received the Dipl. degree in industrial engineering from the Polytechnic University of Cataluna, Barcelona, Spain, in 1982 and the Ph.D. degree in electrical engineering from the Polytechnic University of Madrid. Madrid. Spain, in 1990 .

$\mathrm{He}$ is an Associate Professor in the Electrical Engineering Department at Polytechnic University of Madrid. His curtent tesearch interests include wind energy systems and control drives.

Francisco Blázquez (M07) received the B.S. and Ph.D. degrees in electrical engineering from the Universidad Politécnica de Madrid, Madrid. Spain. in 1998 and 2004 , tespectively.

His curtent interest is wind energy systems. He is now an Assistant Professor at the Universidad Politécnica de Madrid. 
Carlos A. Platero was born in Madrid. Spain, in 1972. He received the Dial. degree in electrical engineering from Universidad Politecnica de Madrid (UPM) in 1996.

He joined ABB Generación S.A. electrical engineering power plant division in 1996. where he was engaged in design and conmissioning of hydro and diesel power plants. Since 2002, he has been an Assistant Professor in the Electrical Engineering Department at UPM, where he works in the Wind Energy Research Group.

Dionisio Ramirez (M'07) was born in Palencia, Spain, in 1966. He received the Dipl. degree in electronic engineering and the Ph.D. degree in electrical engineering from the Universidad Politecnica de Madrid (UPM). Madrid. Spain. in 1997 and 2003 , respectively.

Since 1997, he has been an Associate Professor in the Department of Electrical Engineering at UPM. His current tesearch interests include powet electronic converters and DSP-based control.
Sergio Martinez ( ${ }^{\prime} 03$ ) received the Ph.D. degree in electrical enginerting.

$\mathrm{He}$ is an Associate Professor of electrical engineering at Universidad Politecnica de Madrid, Madrid, Spain. His cutrent research interests include electrical generation form renewable energy and electrical metrology.

Jose A. Sanchez is a Professor of electrical engineering and head of the Department of Civil Engineering: Hydraulics and Energy at the Universidad Politecnica de Madrid, Madrid, Spain. His research interests include hydro and wind energy electric generation and engineering education. $\mathrm{He}$ is author or coauthor of numerous papers in international conferences and journals.

Nieves Herrero-Martínez is an Assistant Professor of electrical engineering at the Untiversidad Politecnica de Madrid, Madrid, Spain. Het tesearch interests include wind energy electric generation and engineering education. She is author or coauthor of numerous papers in international conferences and journals. 